\title{
Medical and Surgical Management of Empyema
}

\author{
Mark S. Godfrey, MD ${ }^{1} \quad$ Kyle T. Bramley, MD ${ }^{1}$ Frank Detterbeck, MD² \\ 1 Pulmonary, Critical Care and Sleep Medicine, Yale New Haven \\ Hospital, New Haven, Connecticut \\ 2 Section of Thoracic Surgery, Yale University School of Medicine,

\begin{abstract}
Address for correspondence Frank Detterbeck, MD, 330 Cedar Street, P.O. Box 208062, New Haven, CT 06520
\end{abstract} \\ (e-mail: frank.detterbeck@yale.edu).
} New Haven, Connecticut

Semin Respir Crit Care Med 2019;40:361-374.

\begin{abstract}
Keywords

- empyema

- pleural infection

- tissue plasminogen activator

- deoxyribonuclease

- thoracoscopy

- video-assisted thoracic surgery

Infection of the pleural space is an ancient and common clinical problem, the incidence which is on the rise. Advances in therapy now present clinicians of varying disciplines with an array of therapeutic options ranging from thoracentesis and chest tube drainage (with or without intrapleural fibrinolytic therapies) to video-assisted thoracic surgery (VATS) or thoracotomy. A framework is provided to guide decision making, which involves weighing multiple factors (clinical history and presentation, imaging characteristics, comorbidities); multidisciplinary collaboration and active management are needed as the clinical course over a few days determines subsequent refinement. The initial choice of antibiotics depends on whether the empyema is community-acquired or nosocomial, and clinicians must recognize that culture results often do not reflect the full disease process. Antibiotics alone are rarely successful and can be justified only in specific circumstances. Early drainage with or without intrapleural fibrinolytics is usually required. This is successful in most patients; however, when surgical decortication is needed, clear benefit and low physiologic impact are more likely with early intervention, expeditious escalation of interventions, and care at a center experienced with VATS.
\end{abstract}

During World War I, the U.S. Army formed an empyema commission to address an epidemic of empyema among enlisted men in crowded camps and exacerbated by the 1918 influenza pandemic. ${ }^{1}$ Their management recommendations were (1) early closed pleural drainage (through serial aspiration or closed chest tube), (2) avoidance of early open drainage, (3) sterilization and obliteration of the empyema cavity, and (4) maintenance of the patient's nutritional status. ${ }^{2}$ One-hundred years later these remain core principles, despite major advances including antibiotic therapy, imaging techniques, intrapleural fibrinolytic drugs, and minimally invasive surgical techniques. Despite these advances, the morbidity, mortality, and burden of pleural infection remain high. Judging which interventions are needed to optimally manage an individual patient is complex and involves qualitative factors. While clinical studies provide guidance, ambiguity in how to apply the evidence remains.

This review aims to provide practical guidance to the general or respiratory physician or surgeon managing a patient with pleural infection. We refer readers to other literature regarding topics not addressed here, such as the clinical and radiographic presentation of pleural infection, ${ }^{3}$ management of postresection pleural space infection and empyema associated with a bronchial or esophageal fistula, ${ }^{4,5}$ nonbacterial (mycobacterial, fungal) empyema, and pleural infection in children. $^{6}$

\section{Incidence and Mortality of Pleural Infection}

Parapneumonic effusion develops in 14 to $19 \%$ of patients with community-acquired pneumonia (CAP), and roughly a third of these patients will have empyema or complicated parapneumonic effusion (CPE) ${ }^{7,8}$ However, the notion that empyema represents an extension of bacterial pneumonia is currently being challenged. Many patients with empyema lack imaging evidence of an underlying pneumonia; in a recent study, chest computed tomography (CT) demonstrated evidence of pneumonia in only 44\% (64/164) of community-acquired empyema
Issue Theme Pleural Diseases; Guest Editors: Jonathan Puchalski, MD, and Najib M. Rahman, DPhil, MSc, FRCP
Copyright (C) 2019 by Thieme Medical Publishers, Inc., 333 Seventh Avenue, New York, NY 10001, USA. Tel: +1(212) 584-4662.
DOI https://doi.org/ 10.1055/s-0039-1694699. ISSN 1069-3424. 
(CAE) cases and $27 \%(88 / 324)$ of health care associated empyema (HCAE). ${ }^{9}$ Retrospective cohorts demonstrate no seasonal variation in empyema incidence, in contrast with the seasonality of pneumonia. The microbiology of CAP is remarkably different from that of CAE (see "Microbiology"). While occasionally pleural infection arises through hematogenous spread, from subdiaphragmatic infection, trauma, or iatrogenically from procedures, the mechanism for the development of many empyemas is unclear.

The crude and/or age-adjusted incidence of adult pleural infection is consistently rising in diverse cohorts and health systems (e.g., in Canada, ${ }^{10,11}$ Denmark, ${ }^{12}$ Finland, ${ }^{13}$ and the United States). ${ }^{14,15}$ The largest incidence ratio increase is in the elderly. ${ }^{11,12}$ Because the 30-day/in-hospital case fatality rate of empyema (7-11\%) has remained stable for over 30 years, ${ }^{14,15}$ the rising incidence is not likely due to improved detection of clinically less-significant disease. This would be expected to dilute the case fatality rate, in fact one study found both an increasing incidence of empyema and incidence of empyema-specific deaths. ${ }^{16}$

Long-term outcomes of patients with pleural infection demonstrate high rates of readmission and repeated interventions. Among 4,095 patients with empyema, $21 \%$ were readmitted within 90 days and $27 \%$ of these readmissions were specifically secondary to the empyema. ${ }^{17}$ Additionally, a subsequent procedure within 30 days was required in 51 and $39 \%$, respectively, of patients managed initially with a chest tube or with initial surgery. ${ }^{17}$ Although their baseline status is unclear, 22 to $31 \%$ of pleural infection patients are reportedly discharged to a facility instead of home. ${ }^{11,14}$

A substantial late mortality is reported after a pleural infection. The 1-, 3-, and 5-year mortality was 15, 24, and $30 \%$, respectively, among 191 patients with empyema or $\mathrm{CPE}^{18}$; their 3-month mortality of $8 \%$ was similar to those of other prospective cohorts. ${ }^{19}$ The majority (66\%) of late mortality in patients with empyema is attributable to causes other than pneumonia or empyema. ${ }^{20}$ Empyema often stems from underlying vulnerability-the high long-term mortality likely reflects these patients' substantial burden of comorbid disease. ${ }^{21}$

\section{General Principles of Management}

\section{Timely Identification of Pleural Infection}

An empyema is defined as pus in the pleural space or pleural fluid with organisms present on Gram stain or culture. CPE is defined as pleural fluid $\mathrm{pH}<7.20$ or pleural fluid glucose $<60 \mathrm{mg} / \mathrm{dL}$ with clinical evidence of infection. However, Gram-stain or culture-positive nonpurulent effusions are defined as "CPE" in some guidelines and reports and as "empyema" in others.

Empyema or CPE should be suspected in any patient with a pleural effusion and pneumonia or sepsis. Reliable demographic or clinical features that indicate empyema associated with CAP have not emerged. ${ }^{22}$ Pleural infection is roughly twice as prevalent in men, ${ }^{11-13,15,23-25}$ in patients with comorbidities (particularly diabetes mellitus, ${ }^{23,24,26-31}$ hypoalbuminemia, ${ }^{7,8}$ and alcoholism). ${ }^{7,8,26,32,33}$ However, the only independent variable associated with empyema
( $n=128$ ) among 1,080 patients with invasive pneumococcal infection was the pneumococcal serotype (not any clinical or demographic features). ${ }^{34}$ Notably, pneumonia-specific and generic sepsis scores (such as the pneumonia severity index or CURB-65) on admission do not predict development of CPE or empyema. ${ }^{8}$

Because there are no clinical characteristics that identify an uncomplicated effusion in patients with pneumonia or sepsis, thoracentesis should be performed whenever such patients have $>10 \mathrm{~mm}$ of pleural fluid. ${ }^{4,35,36}$ A pleural effusion should be specifically sought for when patients with pneumonia fail to respond within 48 to 72 hours of antibiotic therapy, or in elderly patients (who often lack overtly infectious symptoms and present with dyspnea, anemia, or weight loss). ${ }^{37}$

Classification schemas for pleural infection differ regarding pleural fluid glucose thresholds $\left(60^{38}\right.$ vs. $\left.40 \mathrm{mg} / \mathrm{dL}^{35,39}\right)$ and inclusion ${ }^{35,38}$ or not ${ }^{39}$ of pleural fluid lactate dehydrogenase measurement. ${ }^{40}$ All classifications include $\mathrm{pH}$ measurement, but $\mathrm{pH}$ can be affected by residual air, heparin, or lidocaine in the sample, ${ }^{41}$ can significantly vary between individual locules, ${ }^{42}$ or be elevated by urease-producing organisms such as Proteus. ${ }^{43}$ Therefore, a pleural effusion should not be classified and managed as uncomplicated solely by biochemical features; for borderline laboratory results the clinical context of the patient must be considered. Escalating therapy empirically or resampling the effusion is indicated whenever clinical questions linger.

\section{Timely Management of Pleural Infection}

A three-stage classification of parapneumonic effusion (exudative, fibrinopurulent, and organizing) was proposed in $1962 .{ }^{44}$ Early observations suggested that it took 2 to 3 weeks for the early exudate to become frankly purulent. ${ }^{2}$ However, the time to progression from one stage to another is highly variable. Therefore, interventions should be performed expeditiously, and treatments escalated rapidly when the pleural process did not improve within a few days. There is no role for protracted "expectant" management of a potentially infected pleural space; delaying diagnostic thoracentesis of a parapneumonic effusion for an anticipated response to antibiotics alone is associated with increased hospital length of stay (LOS) and costs. ${ }^{45}$ Similarly, delaying a chest tube $>3$ days after recognition of pleural fluid is associated with increased mortality. ${ }^{46}$

Preclinical models of pleural infection have demonstrated rapid progression of pleural organization within hours to days. In a Pasteurella rabbit model, less pleural rind was noted with chest tube placement 24 to 48 hours after pleural inoculation; with chest tube placement after 72 hours the pleura was similar to animals with no chest tube. ${ }^{47}$ In this same model, pus and pleural fibrosis were consistently evident 96 hours after empyema induction. ${ }^{48}$

The time course of human pleural infection appears far more heterogeneous; the evidence generally supports that timely management is beneficial with the caveat that the absolute time interval is quite variable. ${ }^{45,46}$ Surgical series (-Table 1) have generally focused on the rate of intraoperative conversion from video-assisted thoracic surgery (VATS) decortication to open thoracotomy. Delay is variably defined as time 
Table 1 Rates of conversion from initial VATS to thoracotomy in patients with empyema

\begin{tabular}{|c|c|c|c|c|c|c|c|c|}
\hline \multirow[t]{2}{*}{ 1st author, year } & \multirow[t]{2}{*}{ Design } & \multirow[t]{2}{*}{$N$} & \multirow[t]{2}{*}{ Prior therapy } & \multirow{2}{*}{$\begin{array}{l}\text { Empyema } \\
\text { stage }\end{array}$} & \multirow{2}{*}{$\begin{array}{l}\text { 30-day } \\
\text { mort. } \\
\text { (\%) }\end{array}$} & \multirow{2}{*}{$\begin{array}{l}\text { Conversion } \\
\text { rate }(\%)\end{array}$} & \multicolumn{2}{|c|}{ Factors associated with conversion } \\
\hline & & & & & & & Not predictive & Predictive \\
\hline Lawrence $1997^{56}$ & Retrospective & 42 & Failed med tmt & II-III & 0 & $5,29^{a}$ & $\begin{array}{l}\text { Duration of symptoms } \\
\text { Preop hospital stay }\end{array}$ & \\
\hline Striffeler $1998^{146}$ & Retrospective & $67^{\mathrm{b}}$ & Failed med tmt & $\|$ & 4 & 28 & Chest $\mathrm{CT}$ features & None \\
\hline $\begin{array}{l}\text { Angelillo- } \\
\text { Mackinlay } \\
1999^{147}\end{array}$ & Retrospective & 53 & & $\|$ & 2 & 6 & & \\
\hline Cassina $1999^{148}$ & Prospective & 45 & Failed IPFT & $\|$ & $0^{c}$ & 18 & Chest $\mathrm{CT}$ features & \\
\hline Waller $2001^{55}$ & Prospective & 36 & & II-III & 6 & 42 & $\begin{array}{l}\text { Duration of symptoms } \\
\text { Preop hospital stay }\end{array}$ & None \\
\hline Waller $2001^{50}$ & Prospective & 39 & & $\|$ & 3 & 59 & & Preop hospital stay \\
\hline Roberts $2003^{149}$ & Retrospective & 172 & & II-III & 2 & 62 & $\begin{array}{l}\text { CT pleural rind } \\
\text { CT organized fluid }\end{array}$ & CT report "empyema" \\
\hline $\operatorname{Kim} 2004^{54}$ & Retrospective & 70 & Failed med tmt & II-III & 0 & 7 & Duration of symptoms & \\
\hline Lardinois $2005^{51}$ & Prospective & 178 & Chest tube $75 \%$ & $\|$ & 3 & 44 & & $\begin{array}{l}\text { Duration of symptoms } \\
\text { Gram-neg organisms }\end{array}$ \\
\hline Solaini $2007^{150}$ & Retrospective & 110 & Chest tube $65 \%$ & II-III & 0 & 8 & & \\
\hline Cardillo $2009^{151}$ & Retrospective & 185 & Failed med tmt & II-III & 0 & 6 & & $\begin{array}{l}\text { Stage III } \\
\text { Duration of symptoms }\end{array}$ \\
\hline Stefani $2013^{52}$ & Retrospective & 97 & Chest tube $61 \%$ & II-III & - & 59 & $\begin{array}{l}\text { CRP } \\
\text { Positive culture } \\
\text { Loculated effusion }\end{array}$ & $\begin{array}{l}\text { Duration of symptoms } \\
\text { CT pleural rind } \\
\text { Fever }\end{array}$ \\
\hline Chung $2014^{57}$ & Retrospective & $120^{\mathrm{d}}$ & Chest tube $30 \%$ & II-III & 0 & 1 & Duration of symptoms & \\
\hline $\begin{array}{l}\text { Schweigert } \\
2016^{21}\end{array}$ & Retrospective & 335 & & $\mathrm{I}$, II, and III & $9^{c}$ & 13 & & \\
\hline $\begin{array}{l}\text { Jagelavicius } \\
2017^{53}\end{array}$ & Prospective & 71 & & II-III & 1 & 25 & $\begin{array}{l}\text { Chest CT features } \\
\text { CRP, fever } \\
\text { Positive culture }\end{array}$ & $\begin{array}{l}\text { Duration of symptoms } \\
\text { Frank pus }\end{array}$ \\
\hline Reichert $2018^{152}$ & Retrospective & 110 & & III & 11 & 5 & & \\
\hline
\end{tabular}

Abbreviations: CT, computed tomography; neg, negative; IPFT, intrapleural fibrinolytic therapy; med tmt, medical treatment; Preop, preoperative. Note: Empyema stage: I (exudative), II (fibrinopurulent), and III (organized).

antraoperative conversion in 2 of 42 cases (4.8\%), 10 additional patients required open second procedure, so total open is $12 / 42$ (29\%).

bymptom duration <3 wk; no visceral pleural thickening on CT.

'Duration not specified.

d $16 \%$ had tuberculosis.

from hospital admission to operation ${ }^{49,50}$ (precise but with many confounders) or as time from symptom onset to operation (more vague but potentially more reflective of the pathophysiology). The results of these analyses are conflicting and may also reflect the degree of experience with VATS decortication.

Multivariate analysis in several studies totaling 346 patients found that a longer duration of symptoms was associated with a higher rate of conversion from VATS to open thoracotomy (which occurred in $8-44 \%$ of cases). ${ }^{51-53}$ The mean symptom duration in the successful VATS groups was 10 to 20 days compared with 17 to 30 days in the conversion groups. ${ }^{51,52}$ The effect of symptom duration on conversion was continuous (i.e., there was no "inflection point" where management via VATS became difficult $)^{51,53}$; each additional day of symptoms was associated with a greater odds ratio (OR) of conversion of $1.1(1.0-1.2, p=0.004) .^{53}$

However, others have reported low intraoperative conversion rates despite a long average duration of symptoms. ${ }^{54}$ Two series found a similar mean duration of symptoms in VATS cases versus those requiring conversion (38 vs. 40 and
53 vs. 56 days). ${ }^{55,56}$ Among 128 patients with surgically managed empyema, a longer symptom duration $(<2,2-4$, and $>4$ weeks) was associated with a longer operative time (101, 125, and 139 minutes, respectively) and an increased rate of postoperative air leaks; however, there was no difference in the need for reoperation or additional drainage procedures and the rate of intraoperative conversion to thoracotomy was low throughout (only one patient with symptoms $<2$ weeks) ${ }^{57}$ Overall, lower conversion rates in contemporary studies and from centers with more VATS cases suggest that the conversion rate is an unreliable surrogate for increasing organization of the pleural space as it is highly influenced by the surgeon and the setting.

There are little data regarding symptom duration and outcomes of intrapleural fibrinolytic therapy (IPFT). The favorable results of combined tissue plasminogen activator (tPA) and deoxyribonuclease (DNase) in the MIST2 trial (see "Intrapleural Fibrinolytic Therapy") occurred in patients with a median symptom duration of 13 days. ${ }^{24}$ Other retrospective series have reported good outcomes with a duration of symptoms of 9 to 13 days. ${ }^{58,59}$ However, most studies of 
IPFT include patients based on subjective physician judgment and omit mention of symptom duration.

\section{Should Frank Pus Be Managed Differently than Complicated Parapneumonic Effusion?}

The distinction between frank pus and Gram-stain or culturepositive pleural fluid is somewhat arbitrary, and data are conflicting whether this influences outcomes. In unblinded surgical series, purulence is predictive of conversion from VATS to thoracotomy, reoperation, and perioperative mortality. ${ }^{49,53}$ In one retrospective series, the absence of purulence predicted success using tube thoracostomy and streptokinase (positive predictive value [PPV] 93\%), but the presence of purulence did not predict treatment failure (PPV 26\%). ${ }^{60}$ A planned subgroup analysis of two large randomized fibrinolytic trials (MIST1 and MIST2) did not demonstrate a difference in outcomes in purulent and nonpurulent patients. ${ }^{23,24}$ Therefore, the presence of pus should not weigh heavily in choosing how to manage patients with empyema.

\section{Microbiology}

What Is the Microbiologic Yield in Pleural Infection? The bacteriologic yield of empyema/CPE by routine pleural fluid culture is roughly 50\%. ${ }^{24,25,61}$ Frequently, blood cultures are the only positive culture results, so aerobic and anaerobic blood cultures should be obtained whenever pleural infection is suspected. ${ }^{62,63}$ Culture positivity is consistently higher in nosocomial empyema or in intensive care unit patients (typically $72-85 \%)^{49,64-66}$

Several methods have been studied to increase the yield of pleural fluid culture. Inoculation of pleural fluid into blood culture bottles at the bedside (vs. submission to the laboratory in a sterile container) detects more organisms with low rates of contamination. ${ }^{31,63,67}$ The use of polymerase chain reaction (PCR) of $16 \mathrm{~S}$ ribosomal RNA (rRNA) improves the diagnostic yield (82 vs. $55 \%$ with conventional cultures $)^{68}$; the bacteria identified solely by PCR are frequently anaerobes. ${ }^{69,70}$ PCR technology can also be applied to tissue obtained from ultrasound-guided pleural biopsies, which increases the yield compared with conventional culture, again particularly for anaerobes. ${ }^{70}$ However, the overall yield remains 55\% despite combination testing (blood culture, pleural fluid culture, pleural fluid, and pleural biopsy $16 \mathrm{~S}$ rRNA), ${ }^{70}$ and PCR is not routinely available. Therefore, empiric antibiotics must often be guided by an understanding of the bacteria frequently encountered in specific settings.

\section{Bacteriology of Community-Acquired versus Healthcare-Acquired Empyema}

The causative organisms are different if an empyema is community-acquired (CAE) or healthcare-acquired (HCAE). -Table 2 and - Fig. 1 summarize data from several studies of organisms isolated from the pleural fluid of nearly 1,500 patients (CAE, 825 and HCAE, 672). 9,25,31,61,64,66,71,72 In CAE, Streptococcus species account for roughly $50 \%$ of isolates, most commonly nonpneumococcal Strep milleri. Methicillin-resistant Staph aureus (MRSA) is uncommon, though case reports
Table 2 Causative bacteria in community-acquired and hospitalacquired empyema

\begin{tabular}{|c|c|c|}
\hline Organism isolates & $\begin{array}{l}\text { Community- } \\
\text { acquired } \\
\text { empyema } \\
(n=825)\end{array}$ & $\begin{array}{l}\text { Hospital- } \\
\text { acquired } \\
\text { empyema } \\
(n=672)\end{array}$ \\
\hline Aerobic Gram-positives & $745(76 \%)$ & $630(65 \%)$ \\
\hline Streptococcus & $502(51 \%)$ & $169(17 \%)$ \\
\hline Strep milleri ${ }^{\mathrm{a}}$ & $294(30 \%)$ & $136(14 \%)$ \\
\hline Strep pneumoniae & $142(14 \%)$ & $11(1 \%)$ \\
\hline Other strep & $66(7 \%)$ & $22(2 \%)$ \\
\hline Enterococci & $23(2 \%)$ & $73(8 \%)$ \\
\hline Staphylococcus ${ }^{\mathrm{b}}$ & $172(18 \%)$ & $310(32 \%)$ \\
\hline MSSA & $84(9 \%)$ & $103(11 \%)$ \\
\hline MRSA & $26(3 \%)$ & $84(9 \%)$ \\
\hline Other Staph & $37(4 \%)$ & $89(9 \%)$ \\
\hline Other aerobes & $48(5 \%)$ & $78(8 \%)$ \\
\hline Aerobic Gram-negatives & $169(17 \%)$ & $325(33 \%)$ \\
\hline E. coli & $27(3 \%)$ & $31(3 \%)$ \\
\hline Klebsiella & $23(2 \%)$ & $42(4 \%)$ \\
\hline Proteus & $7(1 \%)$ & $4(0 \%)$ \\
\hline Enterobacter & $38(4 \%)$ & $75(8 \%)$ \\
\hline Pseudomonas & $29(3 \%)$ & $70(7 \%)$ \\
\hline Other & $45(5 \%)$ & $103(11 \%)$ \\
\hline Anaerobes & $54(6 \%)$ & $19(2 \%)$ \\
\hline Fusobacterium & $26(3 \%)$ & $3(0 \%)$ \\
\hline Peptostreptococcus & $19(2 \%)$ & $2(0 \%)$ \\
\hline Bacteroides & $20(2 \%)$ & $7(1 \%)$ \\
\hline Prevotella & $16(2 \%)$ & $5(1 \%)$ \\
\hline Other & $29(3 \%)$ & $15(2 \%)$ \\
\hline Other & $17(2 \%)$ & $2(0 \%)$ \\
\hline Total isolates & $985(100 \%)$ & $976(100 \%)$ \\
\hline
\end{tabular}

Abbreviations: MRSA, methicillin-resistant Staph aureus; MSSA, methicillin-sensitive Staph aureus.

Note: Data are presented as number of isolates, $n$ (\%).

Data from 9,25,31,61,64,66,71,72.

ancluding Strep viridians.

${ }^{\mathrm{b}}$ Meyer et al ${ }^{71}$ did not describe Staph aureus resistance.

exist. ${ }^{73}$ In HCAE, Gram-negative organisms are most common (particularly Enterobacter, Pseudomonas, and Klebsiella); Gram-positive isolates are primarily Enterococci and Staph aureus. MRSA appears to be fairly unique to HCAE, in some areas representing $25 \%$ of isolates. ${ }^{61}$ In intensive care unit patients with HCAE, multidrug-resistant pathogens including extended spectrum $\beta$-lactamase (ESBL) producers and Acinetobacter must be considered. ${ }^{65}$

- Table 2 suggests that anaerobes represent less than 5\% of isolates, but this is a gross underestimation of their true prevalence. Anaerobic species (chiefly Bacteroides, Fusobacterium, and Prevotella spp.) are isolated in 74 to $76 \%$ of cases if rapid processing and fastidious culture techniques are 


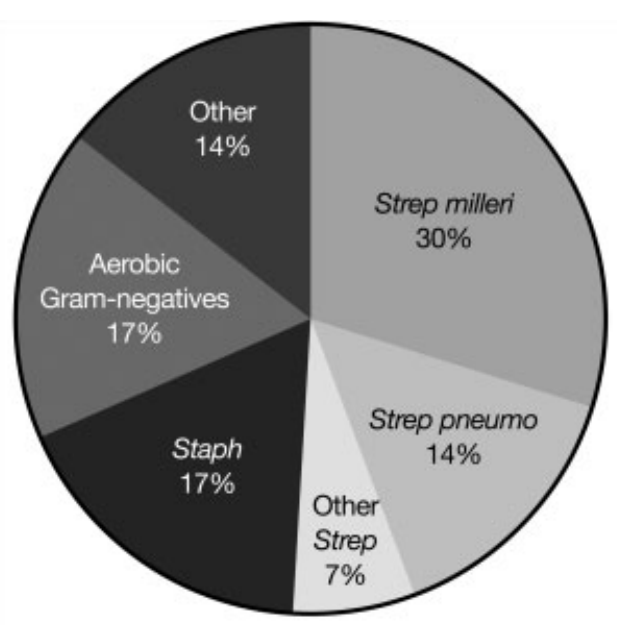

Community-Acquired Empyema

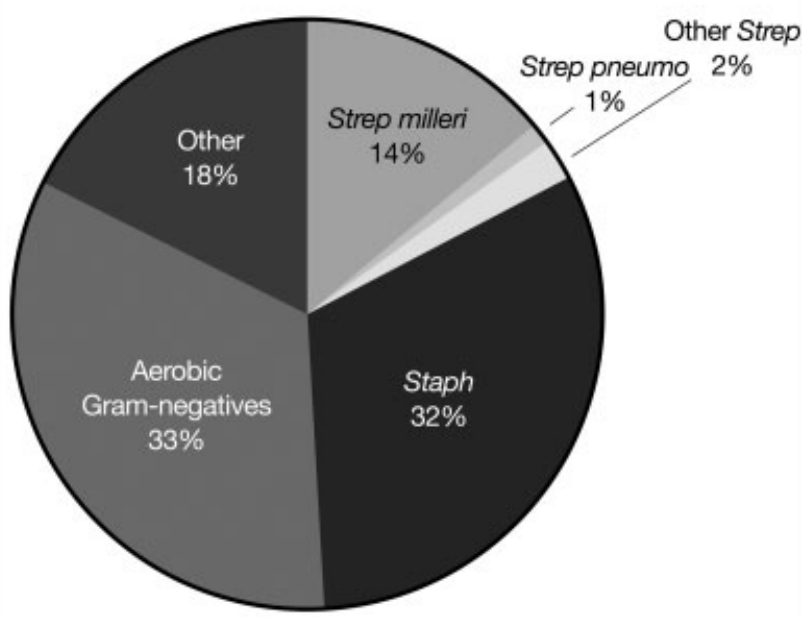

\section{Hospital-Acquired Empyema}

Fig. 1 Causative bacteria from pleural infection in 825 patients with community-acquired infection (top) and 672 patients with hospitalacquired infection (bottom). Data from - Table 2.

employed, or a reference anaerobic microbiology laboratory is used. $^{74-77}$ Furthermore, experimental evidence suggests potential synergy between anaerobes and Strep milleri. ${ }^{78}$ The most compelling evidence for "occult" anaerobes in empyema/ CPE fluid is detection of bacterial DNA or RNA using massive parallel sequencing. This approach identified anaerobic bacteria in 70\% (19/27) patients with empyema and no known etiology (i.e., "primary" CAE), predominantly Fusobacterium nucleatum. By conventional culture only $37 \%$ of cases had growth, and the anaerobes were detected by culture in only $16 \%$ of the anaerobic cases. ${ }^{79}$

When anaerobes are present a longer duration of symptoms is often seen ${ }^{77,80}$ or an atypical presentation, with vague chest pains, weight loss, and anemia-misleading one to suspect malignancy or tuberculosis. ${ }^{29,37,81}$ Fever is also not universal in confirmed anaerobic pleural infection, as shown in one series where $40 \%$ of patients were afebrile and $40 \%$ had low-grade temperatures below $38.9^{\circ} \mathrm{C}{ }^{82}$

When Strep pneumoniae is isolated from pleural fluid, it is usually the only organism, even when advanced diagnostic techniques are employed. ${ }^{61,68-70,79}$ This may be because pneumococcus proliferates rapidly in exudative pleural fluid, ${ }^{83}$ perhaps thereby excluding other bacteria.

\section{Does Culture Positivity or Specific Microbiology Identify High-Risk Patients?}

Culture-positive pleural infection is associated with increased duration of drainage, failure of nonsurgical treatments, longer hospital LOS, complications, and death, compared with culturenegative cases. ${ }^{84,85}$ Retrospective culture-positive cohorts display high in-hospital ${ }^{86}$ as well as 1-year mortality (42-52\% in some series). ${ }^{9,87}$ However, culture positivity is consistently increased in HCAE and critically ill patients ${ }^{49,64-66}$ and outcome differences are not borne out when the setting (HCAE vs. CAE) is taken into account. ${ }^{88}$ Finally, culture positivity does not appear to predict success or failure of fibrinolytic therapy. ${ }^{89}$

In preclinical studies different bacteria may differentially affect pleural mesothelial cells ${ }^{90}$ or upregulate fibrin deposition, ${ }^{91}$ but clinical evidence does not demonstrate that specific bacteria are associated with worse outcomes. Although increased mortality with Gram-negative and Staph infections (irrespective of CAE or HCAE) was shown in one posthoc analysis of the bacteriology from a large, wellcharacterized randomized trial cohort, ${ }^{61}$ subsequent (multivariate) analyses controlling for other factors showed that mortality is primarily dependent on patient factors and setting (CAE or HCAE) and not specific organisms. 9,25,31,65,71 Therefore, culture results should not influence the selection of interventions beyond the choice of antibiotics.

\section{Tube Thoracostomy}

The optimal tube size to drain an empyema/CPE is controversial. The interventional radiology literature reports good outcomes with small $(\leq 14 \mathrm{Fr})$ catheters, but this may also reflect patient selection and precise image-guided tube placement. ${ }^{92,93}$ Surgical series prefer large (32-40 Fr) tubes, with the rationale of reduced tube blockage by viscous fluid. ${ }^{62}$ However, tube thoracostomy failure usually stems from persistent, loculated fluid and not direct tube obstruction.

A secondary analysis of the MIST1 trial provides some insight. ${ }^{94}$ There was no difference in the surgical referral or mortality among groups with chest tubes of varying sizes (<10 Fr 36\% [21/58]; 10-14 Fr 36\% [75/208]; 15-20 Fr 40\% [28/ 70 ]; $>20$ Fr 44\% [30/69]; $p=0.27$ ). Higher pain scores were reported with larger tubes during insertion and while the tube was in place. ${ }^{94}$ However, the original trial left the choice of tube size with the treating physician, and there was a significant trend toward larger tubes in grossly purulent pleural fluid. Nevertheless, a planned analysis of the purulent subgroup did not demonstrate a disadvantage of smaller tubes. ${ }^{94}$

It appears that flushing of the tube is important, particularly with small tubes. In the MIST1 study, all tubes were flushed by protocol several times a day. Other series of small tubes (12 Fr) for nonpurulent CPE which were not routinely flushed found that obstruction occurred in $63 \%(61 / 97) .{ }^{95}$ Therefore, we recommend initial insertion of a small-bore $(\leq 14 \mathrm{Fr})$ tube, but with routine flushing and monitoring for kinking. 


\section{Intrapleural Fibrinolytic Therapy}

\section{Background and Intrapleural Therapy Trials}

Fibrin deposition can lead to pleural loculations and adhesions, inhibiting drainage and lung expansion. An appealing strategy is instillation of IPFT through a chest tube to effect enzymatic debridement. This could reduce the need for surgery, but might delay definitive therapy and increase costs and LOS. In the following sections, "IPFT" refers to the application of any fibrinolytic with or without DNase.

Earlier fibrinolytics, streptokinase and urokinase, have been studied in pleural infection in numerous placebo-controlled human trials with mixed results. ${ }^{96,97}$ A more definitive answer was provided by the multicenter MIST1 study, involving 430 patients with empyema/CPE who received intrapleural streptokinase or placebo. ${ }^{23}$ No difference was found in the rate of death or surgery at 3 months, hospital LOS, radiographic change, or lung function. These findings extended to subgroups of patients analyzed for the presence of loculations or purulent fluid.

The failure of streptokinase to demonstrate benefits over placebo in MIST1 led to the exploration of other agents and targets for enzymatic debridement. Empyema fluid contains extracellular DNA ${ }^{98}$ which increases viscosity, and in animal models the addition of DNase to streptokinase ${ }^{99}$ or $\mathrm{tPA}^{100}$ improved liquefaction and drainage of empyema fluid. DNase may also disrupt bacterial biofilms ${ }^{101}$ and reduce competition for binding to therapeutic fibrinolytics. ${ }^{102}$

This preclinical work, encouraging retrospective series, ${ }^{59,103-106}$ as well as the failure of streptokinase in MIST1, prompted the study of intrapleural tPA, alone or in combination with DNase, in MIST2. ${ }^{24}$ The interventions (tPA at a dose of $10 \mathrm{mg}$, DNase at a dose of $5 \mathrm{mg}$, or placebo) were given in four treatment arms: tPA + DNase, tPA + placebo, placebo + DNase, and placebo + placebo. The combination tPA + DNase arm had significantly reduced radiographic opacification (-30\%) at 7 days (the primary outcome) compared with the other arms which were similar (tPA alone $-17 \%$, DNase alone $-15 \%$, placebo $-17 \%)$. The combination arm also had significantly reduced surgical referral (OR: 0.17; 95\% CI: 0.03-0.87) and significantly shorter hospital LOS (6.7 day reduction; CI: 12.0-1.9) compared with placebo. A reduction in surgical referral was also shown in a subsequent single-center randomized trial of $25 \mathrm{mg}$ of tPA versus placebo in empyema or CPE, though only 6/68 patients included had a positive Gram-stain or frank pus, making generalization of these results difficult. ${ }^{107}$ Recent cost analysis of the MIST2 cohort suggests that tPA + DNase is cost effective, though this should be confirmed in other health systems. $^{108}$

Saline pleural irrigation may be a simple, cost-effective alternative to the MIST2 drugs. In a small $(n=35)$, singlecenter pilot study, patients with pleural infection and incomplete drainage 24 hours after initial tube thoracostomy were randomized to three times daily irrigation with $250 \mathrm{~mL}$ of saline for 3 days versus drainage alone. ${ }^{109}$ Using prespecified indications for surgical referral, the drainage alone group was more likely to require surgery (OR: 7.1 ; 95\% CI: 1.23-41.0; $p=0.03$ ), reflecting a greater remaining effusion on repeat CT as compared with the saline group.

\section{Dosing of IPFT}

The optimal dose, dwell time, dosing frequency, and duration of IPFT are not well defined. Individual doses of tPA range from 2 to $100 \mathrm{mg}^{103,104}$ and dwell times from 30 minutes ${ }^{105}$ to 4 hours. ${ }^{110}$ A prospective study (ADAPT) examined a tPA dose reduction to $5 \mathrm{mg} .{ }^{111}$ Successful treatment (hospital discharge without needing surgery or mortality) occurred in 93\% (57/61), though 5\% experienced pleural bleeding requiring transfusion-similar to studies using higher doses. In this cohort patient selection and symptom duration were unclear, and $13 \%$ had indwelling pleural catheter-associated empyema, which is more likely to respond to antibiotics alone. ${ }^{112}$ Therefore, we recommend fibrinolytic dosing from the MIST2 protocol with a tPA dose of $10 \mathrm{mg}$ and DNase of 5 $\mathrm{mg}$, as dose reductions of the tPA component offer no safety benefits and may not be universally effective.

Preclinical studies demonstrate that the inhibitor of fibrinolysis, plasminogen activator inhibitor-1 (PAI-1), largely accounts for the imbalance between fibrin deposition and fibrinolysis that favors septation and loculation in infected fluid. ${ }^{98,113,114}$ PAI-1 irreversibly inactivates tPA in $1: 1$ fashion and human empyema PAI-1 levels are highly heterogenous, ${ }^{98,115,116}$ suggesting that IPFT dosing relative to measures of fibrin formation may be useful. ${ }^{117}$ Phase I investigation of the fibrinolytic drug single-chain urokinase plasminogen activator (scuPA) that is relatively resistant to inhibition by PAI- 1 is underway. ${ }^{118}$

In patients who failed to respond to the 3-day MIST2 regimen, an extended course of IPFT does not appear to be of benefit. A retrospective comparison of extended tPA and DNase (mean 9.8 doses, range $7-16$ ) versus conventional $(<6)$ doses found similar rates of needing surgery (15 vs. 16\%), but nonsignificant trends toward more bleeding (10 vs. 3\%), additional tube placement ( 35 vs. 15\%), longer LOS (17 vs. 13 days), and greater need to escalate narcotics ( 80 vs. $57 \%) .{ }^{119}$ Presumably extended dose patients were less fit for or refused surgery, but it appears that patients unsuccessfully drained after a short course of IPFT benefit more from additional image-guided tubes or surgery than prolonged IPFT dosing.

\section{Concurrent or Sequential?}

In the MIST2 regimen, twice daily tPA and DNase were instilled sequentially, each allowed to dwell for 1 hour with at least 2 hours of drainage between drugs. ${ }^{24}$ This is cumbersome, and simultaneous instillation of both drugs has been studied in a randomized control trial (RCT) ${ }^{120}$ and retrospective series. ${ }^{30,121}$ The RCT found no significant difference between concurrent (1-hour dwell) versus sequential administration in treatment success ( 75 vs. $78 \%$ ), safety profile, and imaging (CT) improvement. ${ }^{120}$ Retrospective series confirm excellent treatment success (85-90\%) with concurrent administration with a 2-hour dwell time. ${ }^{30,121} \mathrm{~A}$ large, multicenter retrospective study (RetroLysis) of the MIST2 regimen is underway and should provide "real world" dosing and efficacy information. 
Delivery of tPA and DNase simultaneously appears reasonable, and if combined we would suggest administration twice daily with both drugs allowed to dwell for 2 hours. In a rabbit model of tetracycline-induced pleural injury, tPA continued to reduce loculations over 4 to 8 hours. ${ }^{122}$ Two hours, however, has been used in prior studies and is a practical compromise between limiting the time the chest tube is clamped and maximizing effective fibrinolysis.

\section{Safety Profile of Intrapleural Fibrinolytic Therapy}

Fibrinolytic enzymes have a high molecular weight $(70 \mathrm{kDa}$ for tPA) which limits systemic absorption from intrapleural administration. $^{123}$ Intrapleural streptokinase has little measurable effect on systemic fibrinolysis, ${ }^{124,125}$ and intrapleural instillation of $25 \mathrm{mg}$ of tPA has no effect on plasma coagulation profiles and fibrinogen levels. ${ }^{107}$ However, several prospective studies (totaling 465 patients) using intrapleural tPA (5-10 mg) have reported pleural bleeding in 0 to $5 \%$ of cases. ${ }^{24,111,120,126,127}$ The bleeding was managed conservatively in all (transfusion and cessation of IPFT); no patients experienced systemic bleeding. The safety profile of tPA at doses higher than 5 to $10 \mathrm{mg}$ is somewhat conflicting and limited to smaller patient samples. Two small studies suggested an increased risk of intrapleural bleeding at tPA doses of 20 to $25 \mathrm{mg}$ (including intrapleural bleeding requiring operative exploration). ${ }^{106,128}$ However, a randomized crossover trial of $25 \mathrm{mg}$ of tPA versus placebo found a $3 \%$ rate of intrapleural bleeding. ${ }^{107}$ Other retrospective studies suggest that intrapleural bleeding may be idiosyncratic and independent of the tPA dose. ${ }^{103,104}$ These reports used various doses (commonly $50 \mathrm{mg}$ and up to $100 \mathrm{mg}$ ), and only two of 161 patients experienced bleeding at the chest tube site with no intrapleural or systemic bleeds.

A small, single-center retrospective series of intrapleural tPA in anticoagulated or thrombocytopenic patients suggested a safety profile comparable to the cohorts above. ${ }^{129}$ While the risk of systemic bleeding appears to be low, withholding anticoagulation while undergoing IPFT is reasonable if the indication for anticoagulation allows. Should intrapleural bleeding occur, supportive care is generally sufficient.

\section{Medical Thoracoscopy}

Medical thoracoscopy (or pleuroscopy) is typically performed under moderate sedation by a pulmonologist using a single access port and rigid or semirigid instruments. It allows visual inspection, drainage, pleurodesis procedures, and directed parietal pleural biopsy. VATS is usually performed under general anesthesia with single lung ventilation by a surgeon, often with several entry ports and rigid instruments, and allows a full range of thoracic surgical procedures including decortication.

Series of medical thoracoscopy in empyema report success rates (no further interventions required) of between 75 and $91 \%, 85,130,131$ with better results in free-flowing compared with organized empyema. However, in one series, thoracoscopy was performed after an average of 6 days of tube drainage and 18 days from symptom onset. ${ }^{131}$ Medical thoracoscopy can disrupt pleural adhesions but not achieve lung re-expansion when there is a visceral rind, and has limited ability to control bleeding. Clinical trials are ongoing comparing medical thoracoscopy with intrapleural fibrinolysis (NCT02973139 and NCT03468933).

\section{Surgical Therapy}

\section{Medical versus Surgical Therapy}

Two randomized trials compared immediate VATS to tube thoracostomy $\left( \pm\right.$ IPFT) for empyema/CPE. ${ }^{132,133}$ The first found fewer treatment failures (using prespecified criteria), shorter duration of chest tubes and hospitalization in the surgical arm, but involved only a total of 20 patients. $^{132}$ The other RCT $(n=70)$ involved only VATS debridement, but found that immediate VATS was associated with a shorter LOS ( 8 vs. 13 days) and less need for open decortication (17 vs. $37 \%, p<0.05$ ). ${ }^{133}$ However, this trial was unblinded and lacked prespecified criteria for surgical intervention in the medical arm, which occurred more frequently (37\%) than in the placebo arms of MIST1/ MIST2 (14-16\%). ${ }^{23,24}$ Neither study allows conclusions comparing surgery to more effective IPFT regimens with tPA and DNase, and until additional clinical trials (NCT03584113, NCT03583931, and NCT02165891) comparing early VATS to IPFT result, there are no robust data to say that one management strategy is superior.

\section{Which Surgical Approach Is Needed?}

Drainage and IPFT with tPA and DNase can fail in approximately $30 \%$ of patients, who will require surgery if they are candidates. ${ }^{89,120}$ Interpretation of mortality data in surgical cohorts is hindered by patient selection, as population-based studies of empyema report 30-day mortality rates of $11 \%{ }^{14,17}$ whereas many single institutions that primarily performed VATS decortication report 30-day mortality rates of $0 \%$ (-Table 1). Overall, surgically managed patients are younger, less acutely ill, and have fewer comorbidities than those managed nonoperatively; in-hospital mortality in nonoperated patients with empyema/CPE is $15 \%$ compared with 5 to $6 \%$ in patients managed with surgery. ${ }^{14}$

The rate of conversion from a VATS to open decortication in -Table $\mathbf{1}$ is quite variable. It is not clear why-specifically stage of the empyema, symptom duration, study size, publication date, and prior treatment (though infrequently described) do not clearly correlate. Furthermore, attempts to identify factors predictive of conversion within a study are variable-for every study identifying a factor there is another finding no impact. Thoracic surgery generally has transformed from primarily open thoracotomy to primarily VATS approaches, but at varying rates and extent in different centers-this degree of heterogeneous experience with VATS is likely also a factor in single-center/single-operator reports. If available, there is little to be lost by initial VATS exploration in all cases other than a negligible increase in operative time associated with the thoracotomy conversion. 52,55 


\section{Practical Framework for Management}

Many algorithms have been proposed that approach the management of pleural infection as a series of binary choices. ${ }^{3,35,134-137}$ However, actual clinical decision making for individual patients involves simultaneously integrating multiple variables, including patient-related, pleural space characteristics, and availability of expertise and resources. Additionally, management of these patients is best conceptualized as a process, as the treatment response and the course of the illness strongly influence ongoing management.

We recommend active management with multidisciplinary communication between dedicated chest physicians, interventional pulmonologists, and general or thoracic surgeons who share experience in the treatment of pleural infection. It is intuitive that this is beneficial given the complexity of the decision making and the number of factors and interventions involved-however, the impact of such collaboration has not been studied.

\section{Antibiotic Management}

Appropriate antibiotic selection for empyema/CPE is associated with improved survival in multivariate analyses. ${ }^{71,86}$ When available, culture results are informative, but empiric treatment for HCAE or CAE is needed initially and for (frequent) culture-negative cases. For HCAE, coverage should include anaerobes, MRSA, as well as Pseudomonas (e.g., vancomycin, cefepime, and metronidazole, OR vancomycin and piperacillin/ tazobactam dosed for activity against Pseudomonas).

For CAE, coverage should include penicillin-resistant Streptococcus and methicillin-sensitive Staph aureus (MSSA). Anaerobic coverage should be the rule, generally even when a single aerobic pathogen is isolated, because of frequent $(\sim 75 \%)$ coexisting anaerobes-e.g., metronidazole, a $\beta$-lactam plus $\beta$ lactamase inhibitor (amoxicillin-clavulanate, ampicillin-sulbactam, piperacillin-tazobactam), or a carbapenem. If clindamycin is used local resistance patterns should guide coverage for resistant Bacteroides fragilis. Anaerobic coverage can be omitted only with proven pneumococcal infection (as recommended in the British Thoracic Society Guideline). ${ }^{35}$ Addition of a macrolide to cover atypical CAP pathogens (Mycoplasma and Legionella, for example) in empyema is unnecessary. ${ }^{61}$ Empyema due to Legionella is exceptionally rare and associated with small volume effusions. ${ }^{7,138,139}$

The appropriate duration of antimicrobial therapy is unclear. A small study found a trend toward fewer failures with longer courses of parenteral, but not oral, therapy. ${ }^{26}$ Typically, parenteral therapy is continued until objective clinical and biochemical improvement occurs (including adequate pleural drainage)-then changed to oral therapy. The total duration of therapy is generally 3 to 6 weeks, depending on the patient's clinical response.

\section{When Can an Initial Trial of Antibiotics Alone Be Justified?}

“The sun should never set on a parapneumonic effusion."140

There are only a few specific scenarios in which a trial of treatment without an invasive procedure is justified in a patient with signs and symptoms of infection and a pleural effusion (-Fig. 2). Although it is widely believed that stage I (exudative) effusions resolve with antibiotics alone (without drainage), ${ }^{35,39}$ unsuccessful outpatient management with

\section{Invasive Procedure?}
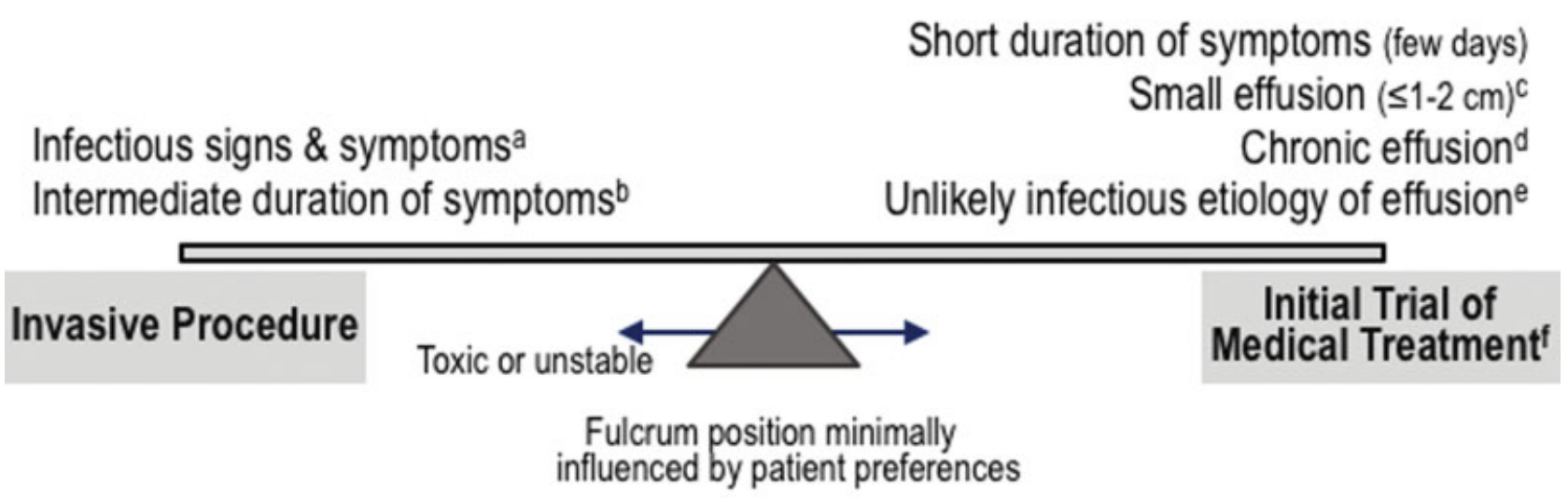

\section{${ }^{a}$ Fever, $\uparrow \mathrm{WBC} / \mathrm{CRP}$, chest wall pain \\ ${ }^{\mathrm{b}}$ several days to few weeks \\ ' distance between inner chest wall and lung \\ d stable effusion over months on prior imaging in the absence of acute symptoms}
${ }^{\ominus}$ underlying conditions associated with effusion (e.g.. $\mathrm{CHF}$, renal failure, ascites)
${ }^{f}$ requires imaging and clinical reassessment within a few days; low threshold for intervention

Fig. 2 Schematic balance of factors for or against trial of antibiotics alone without drainage. There are few specific scenarios in which a trial of treatment without an invasive procedure is justified (see the text for details). CHF, congestive heart failure; CRP, C-reactive protein; WBC, white blood cell. 
antibiotics alone is reported in 28 to $67 \%$ of patients with empyema/CPE. ${ }^{71,72}$ If management with antibiotics alone is attempted in very small (i.e., $1-2 \mathrm{~cm}$ ) effusions, frequent monitoring (including imaging) every few days is needed. The transition from thin fluid to a densely organized process is variable but often occurs within days, and postponing an invasive procedure to directly address the empyema/CPE is clearly associated with prolonged hospital LOS and costs. Delaying interventions is associated with progressively complicated surgical management (e.g., conversion, operative time) which may be partially mitigated by more advanced VATS experience. The general impression is that early drainage is more successful, but the optimal drainage method has not been well studied.

Patient preferences have little impact regarding whether to directly address the pleural process outside of a comfort measures only setting. It is not a question of whether one prefers an invasive procedure or not-the question is whether to do it early or do it later, with associated prolonged hospitalization and increased likelihood of requiring a procedure with greater invasiveness. The risk of thoracentesis or tube placement per se is minimal, even in ICU patients. Too often these relatively minor interventions are deferred due to acuity of illness, comorbidities, or age, when in fact these patients should be managed aggressively as they are the least able to undergo treatment escalation later on.

\section{Choice of Initial Procedure}

Selection of the appropriate invasive procedure involves a multifaceted balance of factors (-Fig. 3). Factors in italics have weaker impact (i.e., less consistently predictive of outcome, or subjective). Accurate symptom duration should be sought; prior imaging even if done only a few days earlier can be very helpful.

It is rare that at least a diagnostic thoracentesis is not needed. Aspiration of cloudy fluid and especially frank pus during thoracentesis indicates the need for at least an indwelling tube but has less predictive power beyond that. The more ill the patient is, the greater the imperative that source of the illness must be fully addressed, so it is generally best to proceed with thoracostomy placement rather than thoracentesis alone. Similarly, in patients with coagulopathy an indwelling tube allows assessment and evacuation of any potential pleural bleeding.

Few patients can be predicted a priori to need surgical intervention. While sonographic (e.g., internal septae, echogenicity) or CT features (e.g., loculations, pleural rind) can suggest that thoracentesis alone is likely insufficient, these features are more variable in predicting whether drainage alone, IPFT, or surgical decortication will be needed..$^{93,141,142}$ Administrative database studies suggest potential overuse of proceeding directly to surgery, perhaps reflective of delayed involvement of clinicians knowledgeable about empyema/ CPE and inexperience with IPFT. However, it is occasionally evident that drainage and IPFT will be suboptimal (multiple separate loculations or extensive fibrosis with contracted ribs and a thick fibrotic rind). If the likelihood is low that drainage and IPFT will be successful, it may be reasonable in good surgical candidates to go directly to surgery. Advanced age alone should not preclude surgical management. ${ }^{143}$

\section{Which Initial Invasive Procedure?}

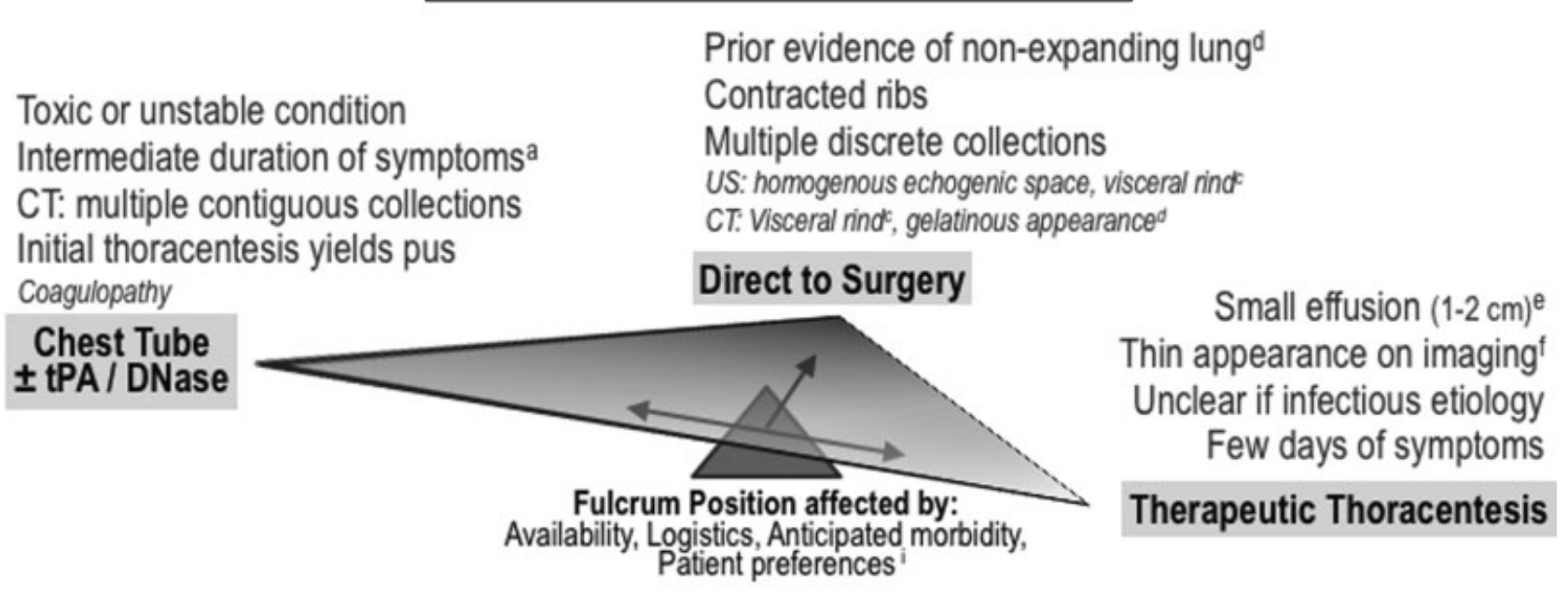

Early multidisciplinary discussion involving medical and surgical specialists advised

\begin{tabular}{|ll|}
\hline a Several days to few weeks & 'Distance between inner chest wall and lung \\
b After drainage, air filling space previously occupied by fluid & f Meniscus, positional layering (e.g. decubitus) or anechoic on US \\
c $>5$ mm, enhancing with IV contrast if assessed with CT & i Must be balanced against strength of medical necessity for \\
intervention
\end{tabular}

Fig. 3 Approach to the initial procedure selection in a patient with suspected pleural infection (i.e., pleural effusion accompanied by sepsis or pneumonia). The factors favoring each procedure (therapeutic thoracentesis, chest tube, or direct surgery) are denoted, with italics indicating minor factors which the authors consider to be more equivocal. See the text for further explanation. DNase, deoxyribonuclease; tPA, tissue plasminogen activator. 
If VATS inspection surprisingly reveals a less organized pleural space that might have responded to drainage and IPFT, little morbidity has occurred and the approach may have nonetheless contributed to a shorter LOS.

\section{Subsequent Procedure(s)}

An early, appropriately chosen initial invasive procedure is sometimes only partially successful. Patients must be followed clinically and with imaging; it is generally clear within 1 to 2 days if further intervention is needed. It is intuitive that proceeding to next steps expeditiously would shorten the duration of the illness, but this has not been studied. Nevertheless, we suggest that rarely is more than 1 day useful to assess whether tube drainage or IPFT has been successful, and active assessment by physicians experienced in empyema/CPE is critical. The patient's clinical condition (fever, white blood cell or C-reactive protein, chest pain, appetite, signs of sepsis) is also an important factor.

High-quality evidence from the MIST2 RCT suggests that tPA + DNase is successful in most patients who fail drainage alone. Although ambiguity remains regarding patient selection, this suggests that at least a brief trial of IPFT is worthwhile in properly selected patients. For simplicity we suggest concurrent instillation of $10 \mathrm{mg}$ tPA and $5 \mathrm{mg}$ DNase with a dwell time of 2 hours (though data defining this as optimal are soft).

Treatment is not needed if pleural thickening or small sterile fluid cavities remain in patients whose clinical signs and symptoms of infection have resolved. Such residual pleural findings often resolve on long-term follow-up. ${ }^{144,145}$

\section{Conclusion}

The challenge in management of thoracic empyema lies in the fact that the "outcome" of the empyema in a given patient represents the interaction of three highly variable domains: host/pathogen factors (patient comorbid diseases, physiologic reserves, and host immune responses), pleural space factors (the degree of macroscopic organization and loculation, pleural fluid biochemistry, and fibrinolytic inhibitor levels), and therapeutic interventions (antimicrobials, drainage, IPFT, surgery, and the timeliness of therapy or lack thereof). The independent contributions of patient and pleural space factors to the outcome, as well as the degree to which they are modifiable by interventions, remain in many cases undefined, and there is no one key factor or treatment decision that consistently will predict outcomes in most patients. Although empyema has been described since the time of Hippocrates, much practice remains based on historical convention. It is only through improved early risk stratification, patient selection, and personalization of therapies that clinicians will be able to fundamentally alter the course of this common and highly morbid clinical problem.

\footnotetext{
Disclosure Statement

The authors have no relationship with a commercial company that has a direct financial interest in subject matter or materials discussed in the article or with a company making a competing product.
}

\section{References}

1 Tung J, Carter D, Rappold J. Empyema commission of 1918Impact on acute care surgery 100 years later. J Trauma Acute Care Surg 2019;86(02):321-325

2 The Empyema Commission. Cases of empyema at Camp Lee, VA: preliminary report. JAMA 1918;71(05):366-373

3 Light RW. Pleural Diseases. 6th ed. Philadelphia, PA: Wolters Kluwer; 2013

4 Scarci M, Abah U, Solli P, et al. EACTS expert consensus statement for surgical management of pleural empyema. Eur J Cardiothorac Surg 2015;48(05):642-653

5 Zahid I, Routledge T, Billè A, Scarci M. What is the best treatment of postpneumonectomy empyema? Interact Cardiovasc Thorac Surg 2011;12(02):260-264

6 Balfour-Lynn IM, Abrahamson E, Cohen G, et al. BTS guidelines for the management of pleural infection in children. Thorax 2005;60(Suppl 1):i1-21

7 Falguera M, Carratalà J, Bielsa S, et al. Predictive factors, microbiology and outcome of patients with parapneumonic effusion. Eur Respir J 2011;38(05):1173-1179

8 Chalmers JD, Singanayagam A, Murray MP, Scally C, Fawzi A, Hill AT. Risk factors for complicated parapneumonic effusion and empyema on presentation to hospital with community-acquired pneumonia. Thorax 2009;64(07):592-597

9 Brims F, Popowicz N, Rosenstengel A, et al. Bacteriology and clinical outcomes of patients with culture-positive pleural infection in Western Australia: a 6-year analysis. Respirology 2019;24 (02):171-178

10 Nayak R, Lougheed MD, Brogly S, Lajkosz K, Petsikas D. Thoracic empyema - 20 year trends in management and outcomes in Ontario, Canada. Am J Respir Crit Care Med 2018;197: A4215

11 Finley C, Clifton J, Fitzgerald JM, Yee J. Empyema: an increasing concern in Canada. Can Respir J 2008;15(02):85-89

12 Søgaard M, Nielsen RB, Nørgaard M, Kornum JB, Schønheyder HC, Thomsen RW. Incidence, length of stay, and prognosis of hospitalized patients with pleural empyema: a 15-year Danish nationwide cohort study. Chest 2014;145(01):189-192

13 Lehtomäki A, Nevalainen R, Ukkonen M, Nieminen J, Laurikka J, Khan J. Trends in the incidence, etiology, treatment, and outcomes of pleural infections in adults over a decade in a Finnish University hospital. Scand J Surg 2019 (e-pub ahead of print): Doi: $10.1177 / 1457496919832146$

14 Farjah F, Symons RG, Krishnadasan B, Wood DE, Flum DR. Management of pleural space infections: a population-based analysis. J Thorac Cardiovasc Surg 2007;133(02):346-351

15 Grijalva CG, Zhu Y, Nuorti JP, Griffin MR. Emergence of parapneumonic empyema in the USA. Thorax 2011;66(08):663-668

16 Bender JM, Ampofo K, Sheng X, Pavia AT, Cannon-Albright L, Byington CL. Parapneumonic empyema deaths during past century, Utah. Emerg Infect Dis 2009;15(01):44-48

17 Semenkovich TR, Olsen MA, Puri V, Meyers BF, Kozower BD. Current state of empyema management. Ann Thorac Surg 2018; 105(06):1589-1596

18 Khan JA, Lehtomäki AI, Toikkanen VJ, Ukkonen MT, Nevalainen RM, Laurikka JO. Long-term prognosis and causes of death after pleural infections. Scand J Surg 2018;107(02):145-151

19 Rahman NM, Kahan BC, Miller RF, Gleeson FV, Nunn AJ, Maskell NA. A clinical score (RAPID) to identify those at risk for poor outcome at presentation in patients with pleural infection. Chest 2014;145(04):848-855

20 Mikkola R, Kelahaara J, Heikkinen J, Lahtinen J, Biancari F. Poor late survival after surgical treatment of pleural empyema. World J Surg 2010;34(02):266-271

21 Schweigert M, Solymosi N, Dubecz A, et al. Surgery for parapneumonic pleural empyema-what influence does the rising prevalence of multimorbidity and advanced age has on the current outcome? Surgeon 2016;14(02):69-75 
22 Ahmed RA, Marrie TJ, Huang JQ. Thoracic empyema in patients with community-acquired pneumonia. Am J Med 2006;119(10): 877-883

23 Maskell NA, Davies CWH, Nunn AJ, et al; First Multicenter Intrapleural Sepsis Trial (MIST1) Group. U.K. controlled trial of intrapleural streptokinase for pleural infection. N Engl J Med 2005;352(09):865-874

24 Rahman NM, Maskell NA, West A, et al. Intrapleural use of tissue plasminogen activator and DNase in pleural infection. $\mathrm{N}$ Engl J Med 2011;365(06):518-526

25 Marks DJB, Fisk MD, Koo CY, et al. Thoracic empyema: a 12-year study from a UK tertiary cardiothoracic referral centre. PLoS One 2012;7(01):e30074

26 Birkenkamp K, O'Horo JC, Kashyap R, et al. Empyema management: a cohort study evaluating antimicrobial therapy. J Infect 2016;72(05):537-543

27 Misthos P, Sepsas E, Konstantinou M, Athanassiadi K, Skottis I, Lioulias A. Early use of intrapleural fibrinolytics in the management of postpneumonic empyema. A prospective study. Eur J Cardiothorac Surg 2005;28(04):599-603

28 Tong BC, Hanna J, Toloza EM, et al. Outcomes of video-assisted thoracoscopic decortication. Ann Thorac Surg 2010;89(01): 220-225

29 Sullivan KM, O'Toole RD, Fisher RH, Sullivan KN. Anaerobic empyema thoracis. The role of anaerobes in 226 cases of culture-proven empyemas. Arch Intern Med 1973;131(04):521-527

30 Majid A, Kheir F, Folch A, et al. Concurrent intrapleural instillation of tissue plasminogen activator and DNase for pleural infection. A single-center experience. Ann Am Thorac Soc 2016;13(09):1512-1518

31 Park C-K, Oh H-J, Choi H-Y, et al. Microbiological characteristics and predictive factors for mortality in pleural infection: a singlecenter cohort study in Korea. PLoS One 2016;11(08):e0161280

32 Alfageme I, Muñoz F, Peña N, Umbría S. Empyema of the thorax in adults. Etiology, microbiologic findings, and management. Chest 1993;103(03):839-843

33 LeMense GP, Strange C, Sahn SA. Empyema thoracis. Therapeutic management and outcome. Chest 1995;107(06):1532-1537

34 Burgos J, Lujan M, Falcó V, et al. The spectrum of pneumococcal empyema in adults in the early 21st century. Clin Infect Dis 2011; 53(03):254-261

35 Davies HE, Davies RJO, Davies CWH, BTS Pleural Disease Guideline Group. Management of pleural infection in adults: British Thoracic Society Pleural Disease Guideline 2010. Thorax 2010; 65(Suppl 2):ii41-ii53

36 Shen KR, Bribriesco A, Crabtree T, et al. The American Association for Thoracic Surgery consensus guidelines for the management of empyema. J Thorac Cardiovasc Surg 2017;153(06):e129-e146

37 El Solh AA, Alhajjhasan A, Ramadan FH, Pineda LA. A comparative study of community- and nursing home-acquired empyema thoracis. J Am Geriatr Soc 2007;55(11):1847-1852

38 Light RW. Parapneumonic effusions and empyema. Proc Am Thorac Soc 2006;3(01):75-80

39 Colice GL, Curtis A, Deslauriers J, et al. Medical and surgical treatment of parapneumonic effusions : an evidence-based guideline. Chest 2000;118(04):1158-1171

40 Light RW. A new classification of parapneumonic effusions and empyema. Chest 1995;108(02):299-301

41 Rahman NM, Mishra EK, Davies HE, Davies RJO, Lee YCG. Clinically important factors influencing the diagnostic measurement of pleural fluid pH and glucose. Am J Respir Crit Care Med 2008; 178(05):483-490

42 Maskell NA, Gleeson FV, Darby M, Davies RJO. Diagnostically significant variations in pleural fluid $\mathrm{pH}$ in loculated parapneumonic effusions. Chest 2004;126(06):2022-2024

43 Pine JR, Hollman JL. Elevated pleural fluid pH in Proteus mirabilis empyema. Chest 1983;84(01):109-111
44 Andrews N, Parker E, Shaw R, Wilson N, Webb W. Management of nontuberculous empyema: a statement of the subcommittee on surgery. Am Rev Respir Dis 1962;85:935-936

45 Heffner JE, McDonald J, Barbieri C, Klein J. Management of parapneumonic effusions. An analysis of physician practice patterns. Arch Surg 1995;130(04):433-438

46 Ashbaugh DG. Empyema thoracis. Factors influencing morbidity and mortality. Chest 1991;99(05):1162-1165

47 Sasse S, Nguyen TK, Mulligan M, Wang NS, Mahutte CK, Light RW. The effects of early chest tube placement on empyema resolution. Chest 1997;111(06):1679-1683

48 Sasse SA, Causing LA, Mulligan ME, Light RW. Serial pleural fluid analysis in a new experimental model of empyema. Chest 1996; 109(04):1043-1048

49 Luh S-P, Chou M-C, Wang L-S, Chen J-Y, Tsai T-P. Video-assisted thoracoscopic surgery in the treatment of complicated parapneumonic effusions or empyemas: outcome of 234 patients. Chest 2005;127(04):1427-1432

50 Waller DA, Rengarajan A, Nicholson FHG, Rajesh PB. Delayed referral reduces the success of video-assisted thoracoscopic debridement for post-pneumonic empyema. Respir Med 2001; 95(10):836-840

51 Lardinois D, Gock M, Pezzetta E, et al. Delayed referral and gramnegative organisms increase the conversion thoracotomy rate in patients undergoing video-assisted thoracoscopic surgery for empyema. Ann Thorac Surg 2005;79(06):1851-1856

52 Stefani A, Aramini B, della Casa G, et al. Preoperative predictors of successful surgical treatment in the management of parapneumonic empyema. Ann Thorac Surg 2013;96(05):1812-1819

53 Jagelavicius Z, Jovaisas V, Mataciunas M, Samalavicius NE, Janilionis R. Preoperative predictors of conversion in thoracoscopic surgery for pleural empyema. Eur J Cardiothorac Surg 2017;52 (01):70-75

54 Kim B-Y, Oh B-S, Jang W-C, Min Y-I, Park Y-K, Park J-C. Videoassisted thoracoscopic decortication for management of postpneumonic pleural empyema. Am J Surg 2004;188(03):321-324

55 Waller DA, Rengarajan A. Thoracoscopic decortication: a role for video-assisted surgery in chronic postpneumonic pleural empyema. Ann Thorac Surg 2001;71(06):1813-1816

56 Lawrence DR, Ohri SK, Moxon RE, Townsend ER, Fountain SW. Thoracoscopic debridement of empyema thoracis. Ann Thorac Surg 1997;64(05):1448-1450

57 Chung JH, Lee SH, Kim KT, Jung JS, Son HS, Sun K. Optimal timing of thoracoscopic drainage and decortication for empyema. Ann Thorac Surg 2014;97(01):224-229

58 Moulton JS, Benkert RE, Weisiger KH, Chambers JA. Treatment of complicated pleural fluid collections with image-guided drainage and intracavitary urokinase. Chest 1995;108(05):1252-1259

59 Levinson GM, Pennington DW. Intrapleural fibrinolytics combined with image-guided chest tube drainage for pleural infection. Mayo Clin Proc 2007;82(04):407-413

60 Davies CW, Kearney SE, Gleeson FV, Davies RJ. Predictors of outcome and long-term survival in patients with pleural infection. Am J Respir Crit Care Med 1999;160(5, Pt 1):1682-1687

61 Maskell NA, Batt S, Hedley EL, Davies CWH, Gillespie SH, Davies RJO. The bacteriology of pleural infection by genetic and standard methods and its mortality significance. Am J Respir Crit Care Med 2006;174(07):817-823

62 Mandal AK, Thadepalli H, Mandal AK, Chettipally U. Outcome of primary empyema thoracis: therapeutic and microbiologic aspects. Ann Thorac Surg 1998;66(05):1782-1786

63 Ferrer A, Osset J, Alegre J, et al. Prospective clinical and microbiological study of pleural effusions. Eur J Clin Microbiol Infect Dis 1999;18(04):237-241

64 Koma Y, Inoue S, Oda N, et al. Clinical characteristics and outcomes of patients with community-acquired, health-care-associated and hospital-acquired empyema. Clin Respir J 2017;11(06):781-788 
65 Lin YC, Chen HJ, Liu YH, Shih C-M, Hsu W-H, Tu C-Y. A 30-month experience of thoracic empyema in a tertiary hospital: emphasis on differing bacteriology and outcome between the medical intensive care unit (MICU) and medical ward. South Med J 2008;101(05):484-489

66 Tu C-Y, Hsu W-H, Hsia T-C, et al. The changing pathogens of complicated parapneumonic effusions or empyemas in a medical intensive care unit. Intensive Care Med 2006;32(04):570-576

67 Menzies SM, Rahman NM, Wrightson JM, et al. Blood culture bottle culture of pleural fluid in pleural infection. Thorax 2011; 66(08):658-662

68 Insa R, Marín M, Martín A, et al. Systematic use of universal 16S rRNA gene polymerase chain reaction (PCR) and sequencing for processing pleural effusions improves conventional culture techniques. Medicine (Baltimore) 2012;91(02):103-110

69 Kawanami T, Fukuda K, Yatera K, Kido M, Mukae H, Taniguchi H. A higher significance of anaerobes: the clone library analysis of bacterial pleurisy. Chest 2011;139(03):600-608

70 Psallidas I, Kanellakis NI, Bhatnagar R, et al. A pilot feasibility study in establishing the role of ultrasound-guided pleural biopsies in pleural infection (the AUDIO study). Chest 2018; 154(04):766-772

71 Meyer CN, Rosenlund S, Nielsen J, Friis-Møller A. Bacteriological aetiology and antimicrobial treatment of pleural empyema. Scand J Infect Dis 2011;43(03):165-169

72 Lindstrom ST, Kolbe J. Community acquired parapneumonic thoracic empyema: predictors of outcome. Respirology 1999;4 (02):173-179

73 Micek ST, Dunne M, Kollef MH. Pleuropulmonary complications of Panton-Valentine leukocidin-positive community-acquired methicillin-resistant Staphylococcus aureus: importance of treatment with antimicrobials inhibiting exotoxin production. Chest 2005;128(04):2732-2738

74 Bartlett JG, Gorbach SL, Thadepalli H, Finegold SM. Bacteriology of empyema. Lancet 1974;1(7853):338-340

75 Boyanova L, Djambazov V, Gergova G, et al. Anaerobic microbiology in 198 cases of pleural empyema: a Bulgarian study. Anaerobe 2004;10(05):261-267

76 Brook I, Frazier EH. Aerobic and anaerobic microbiology of empyema. A retrospective review in two military hospitals. Chest 1993;103(05):1502-1507

77 Civen R, Jousimies-Somer H, Marina M, Borenstein L, Shah H, Finegold SM. A retrospective review of cases of anaerobic empyema and update of bacteriology. Clin Infect Dis 1995;20 (Suppl 2):S224-S229

78 Shinzato T, Saito A. A mechanism of pathogenicity of "Streptococcus milleri group" in pulmonary infection: synergy with an anaerobe. J Med Microbiol 1994;40(02):118-123

79 Dyrhovden R, Nygaard RM, Patel R, Ulvestad E, Kommedal Ø. The bacterial aetiology of pleural empyema. A descriptive and comparative metagenomic study. Clin Microbiol Infect 2019;25(08): 981-986

80 Chen KY, Hsueh PR, Liaw YS, Yang PC, Luh KT. A 10-year experience with bacteriology of acute thoracic empyema: emphasis on Klebsiella pneumoniae in patients with diabetes mellitus. Chest 2000; 117(06):1685-1689

81 Bartlett JG, Finegold SM. Anaerobic infections of the lung and pleural space. Am Rev Respir Dis 1974;110(01):56-77

82 Landay MJ, Christensen EE, Bynum LJ, Goodman C. Anaerobic pleural and pulmonary infections. AJR Am J Roentgenol 1980; 134(02):233-240

83 Popowicz ND, Lansley SM, Cheah HM, et al. Human pleural fluid is a potent growth medium for Streptococcus pneumoniae. PLoS One 2017;12(11):e0188833

84 Okiror L, Coltart C, Bille A, et al. Thoracotomy and decortication: impact of culture-positive empyema on the outcome of surgery. Eur J Cardiothorac Surg 2014;46(05):901-906
85 Brutsche MH, Tassi G-F, Györik S, et al. Treatment of sonographically stratified multiloculated thoracic empyema by medical thoracoscopy. Chest 2005;128(05):3303-3309

86 Nielsen J, Meyer CN, Rosenlund S. Outcome and clinical characteristics in pleural empyema: a retrospective study. Scand J Infect Dis 2011;43(6-7):430-435

87 White HD, Henry C, Stock EM, Arroliga AC, Ghamande S. Predicting long-term outcomes in pleural infections. RAPID score for risk stratification. Ann Am Thorac Soc 2015;12(09):1310-1316

88 Meyer CN, Armbruster K, Kemp M, Thomsen TR, Dessau RB; Danish Pleural Empyema group. Pleural infection: a retrospective study of clinical outcome and the correlation to known etiology, co-morbidity and treatment factors. BMC Pulm Med 2018;18(01):160

89 Khemasuwan D, Sorensen J, Griffin DC. Predictive variables for failure in administration of intrapleural tissue plasminogen activator/deoxyribonuclease in patients with complicated parapneumonic effusions/empyema. Chest 2018;154(03):550-556

90 Rashwan R, Varano Della Vergiliana JF, Lansley SM, et al. Streptococcus pneumoniae potently induces cell death in mesothelial cells. PLoS One 2018;13(07):e0201530

91 Lee K-L, Chen W-L, Chen R-J, Lai KS, Chung C-L. Lipoteichoic acid upregulates plasminogen activator inhibitor- 1 expression in parapneumonic effusions. Respirology 2018;23(01):89-95

92 Keeling AN, Leong S, Logan PM, Lee MJ. Empyema and effusion: outcome of image-guided small-bore catheter drainage. Cardiovasc Intervent Radiol 2008;31(01):135-141

93 Shankar S, Gulati M, Kang M, Gupta S, Suri S. Image-guided percutaneous drainage of thoracic empyema: can sonography predict the outcome? Eur Radiol 2000;10(03):495-499

94 Rahman NM, Maskell NA, Davies CWH, et al. The relationship between chest tube size and clinical outcome in pleural infection. Chest 2010;137(03):536-543

95 Cafarotti S, Dall'Armi V, Cusumano G, et al. Small-bore wire-guided chest drains: safety, tolerability, and effectiveness in pneumothorax, malignant effusions, and pleural empyema.J Thorac Cardiovasc Surg 2011;141(03):683-687

96 Janda S, Swiston J. Intrapleural fibrinolytic therapy for treatment of adult parapneumonic effusions and empyemas: a systematic review and meta-analysis. Chest 2012;142(02):401-411

97 Nie W, Liu Y, Ye J, et al. Efficacy of intrapleural instillation of fibrinolytics for treating pleural empyema and parapneumonic effusion: a meta-analysis of randomized control trials. Clin Respir J 2014;8(03):281-291

98 Komissarov AA, Florova G, Azghani AO, et al. Dose dependency of outcomes of intrapleural fibrinolytic therapy in new rabbit empyema models. Am J Physiol Lung Cell Mol Physiol 2016;311(02):L389-L399

99 Light RW, Nguyen T, Mulligan ME, Sasse SA. The in vitro efficacy of varidase versus streptokinase or urokinase for liquefying thick purulent exudative material from loculated empyema. Hai 2000; 178(01):13-18

100 Zhu Z, Hawthorne ML, Guo Y, et al. Tissue plasminogen activator combined with human recombinant deoxyribonuclease is effective therapy for empyema in a rabbit model. Chest 2006;129(06): 1577-1583

101 Whitchurch CB, Tolker-Nielsen T, Ragas PC, Mattick JS. Extracellular DNA required for bacterial biofilm formation. Science 2002; 295(5559):1487

102 Komissarov AA, Florova G, Idell S. Effects of extracellular DNA on plasminogen activation and fibrinolysis. J Biol Chem 2011;286 (49):41949-41962

103 Skeete DA, Rutherford EJ, Schlidt SA, Abrams JE, Parker LA, Rich $\mathrm{PB}$. Intrapleural tissue plasminogen activator for complicated pleural effusions. J Trauma 2004;57(06):1178-1183

104 Thommi G, Nair CK, Aronow WS, Shehan C, Meyers P, McLeay M. Efficacy and safety of intrapleural instillation of alteplase in the management of complicated pleural effusion or empyema. Am J Ther 2007;14(04):341-345 
105 Gervais DA, Levis DA, Hahn PF, Uppot RN, Arellano RS, Mueller PR. Adjunctive intrapleural tissue plasminogen activator administered via chest tubes placed with imaging guidance: effectiveness and risk for hemorrhage. Radiology 2008;246 (03):956-963

106 Froudarakis ME, Kouliatsis G, Steiropoulos P, et al. Recombinant tissue plasminogen activator in the treatment of pleural infections in adults. Respir Med 2008;102(12):1694-1700

107 Thommi G, Shehan JC, Robison KL, Christensen M, Backemeyer LA, McLeay MT. A double blind randomized cross over trial comparing rate of decortication and efficacy of intrapleural instillation of alteplase vs placebo in patients with empyemas and complicated parapneumonic effusions. Respir Med 2012; 106(05):716-723

108 Luengo-Fernandez R, Penz E, Dobson M, et al. Cost-effectiveness of intrapleural use of tissue plasminogen activator and DNase in pleural infection: evidence from the MIST2 randomised controlled trial. Eur Respir J 2019 (e-pub ahead of print). Doi: 10.1183/13993003.01550-2018

109 Hooper CE, Edey AJ, Wallis A, et al. Pleural irrigation trial (PIT): a randomised controlled trial of pleural irrigation with normal saline versus standard care in patients with pleural infection. Eur Respir J 2015;46(02):456-463

110 Heimes J, Copeland $\mathrm{H}$, Lulla A, et al. The use of thrombolytics in the management of complex pleural fluid collections. J Thorac Dis 2017;9(05):1310-1316

111 Popowicz N, Bintcliffe O, De Fonseka D, et al. Dose de-escalation of intrapleural tissue plasminogen activator therapy for pleural infection. The alteplase dose assessment for pleural infection therapy project. Ann Am Thorac Soc 2017;14(06):929-936

112 Fysh ETH, Tremblay A, Feller-Kopman D, et al. Clinical outcomes of indwelling pleural catheter-related pleural infections: an international multicenter study. Chest 2013;144(05):1597-1602

113 Komissarov AA, Rahman N, Lee YCG, et al. Fibrin turnover and pleural organization: bench to bedside. Am J Physiol Lung Cell Mol Physiol 2018;314(05):L757-L768

114 Florova G, Azghani A, Karandashova S, et al. Targeting of plasminogen activator inhibitor 1 improves fibrinolytic therapy for tetracycline-induced pleural injury in rabbits. Am J Respir Cell Mol Biol 2015;52(04):429-437

115 Philip-Joët F, Alessi MC, Philip-Joët C, et al. Fibrinolytic and inflammatory processes in pleural effusions. Eur Respir J 1995; 8(08):1352-1356

116 Lin F-C, Chen Y-C, Chen F-J, Chang S-C. Cytokines and fibrinolytic enzymes in tuberculous and parapneumonic effusions. Clin Immunol 2005;116(02):166-173

117 Idell S, Florova G, Shetty S, et al. Precision-guided, personalized intrapleural fibrinolytic therapy for empyema and complicated parapneumonic pleural effusions: the case for the fibrinolytic potential. Clin Pulm Med 2017;24(04):163-169

118 Beckert L, Brockway B, Simpson G, et al. Phase 1 trial of intrapleural LTI-01; single chain urokinase in complicated parapneumonic effusions or empyema. JCI Insight 2019;5:127470

119 McClune JR, Wilshire CL, Gorden JA, et al. Safety and efficacy of intrapleural tissue plasminogen activator and DNase during extended use in complicated pleural space infections. Can Respir J 2016;2016:9796768

120 Kheir F, Cheng G, Rivera E, et al. Concurrent versus sequential intrapleural instillation of tissue plasminogen activator and deoxyribonuclease for pleural infection. J Bronchology Interv Pulmonol 2018;25(02):125-131

121 Bishwakarma R, Shah S, Frank L, Zhang W, Sharma G, Nishi SPE. Mixing it up: coadministration of tPA/DNase in complicated parapneumonic pleural effusions and empyema. J Bronchology Interv Pulmonol 2017;24(01):40-47

122 Komissarov AA, Florova G, Azghani AO, et al. The time course of resolution of adhesions during fibrinolytic therapy in tetracy- cline-induced pleural injury in rabbits. Am J Physiol Lung Cell Mol Physiol 2015;309(06):L562-L572

123 Piccolo F, Popowicz N, Wong D, Lee YCG. Intrapleural tissue plasminogen activator and deoxyribonuclease therapy for pleural infection. J Thorac Dis 2015;7(06):999-1008

124 Davies CW, Lok S, Davies RJO. The systemic fibrinolytic activity of intrapleural streptokinase. Am J Respir Crit Care Med 1998;157 (01):328-330

125 Berglin E, Ekroth R, Teger-Nilsson AC, William-Olsson G. Intrapleural instillation of streptokinase. Effects on systemic fibrinolysis. Thorac Cardiovasc Surg 1981;29(02):124-126

126 Mehta HJ, Biswas A, Penley AM, Cope J, Barnes M, Jantz MA. Management of intrapleural sepsis with once daily use of tissue plasminogen activator and deoxyribonuclease. Respiration 2016;91(02):101-106

127 Piccolo F, Pitman N, Bhatnagar R, et al. Intrapleural tissue plasminogen activator and deoxyribonuclease for pleural infection. An effective and safe alternative to surgery. Ann Am Thorac Soc 2014;11(09):1419-1425

128 Alemán C, Porcel JM, Alegre J, et al. Intrapleural fibrinolysis with urokinase versus alteplase in complicated parapneumonic pleural effusions and empyemas: a prospective randomized study. Hai 2015;193(06):993-1000

129 Godfrey MS, Puchalski J. Nondraining indwelling pleural catheters in malignant pleural effusion: how safe is fibrinolysis in patients at high risk of bleeding? Am J Respir Crit Care Med 2019; 199:A1256

130 Ravaglia C, Gurioli C, Tomassetti S, et al. Is medical thoracoscopy efficient in the management of multiloculated and organized thoracic empyema? Respiration 2012;84(03):219-224

131 Solèr M, Wyser C, Bolliger CT, Perruchoud AP. Treatment of early parapneumonic empyema by "medical" thoracoscopy. Schweiz Med Wochenschr 1997;127(42):1748-1753

132 Wait MA, Sharma S, Hohn J, Dal Nogare A. A randomized trial of empyema therapy. Chest 1997;111(06):1548-1551

133 Bilgin M, Akcali Y, Oguzkaya F. Benefits of early aggressive management of empyema thoracis. ANZ J Surg 2006;76(03): 120-122

134 Feller-Kopman D, Light R. Pleural disease. N Engl J Med 2018;378 (08):740-751

135 Corcoran JP, Wrightson JM, Belcher E, DeCamp MM, Feller-Kopman D, Rahman NM. Pleural infection: past, present, and future directions. Lancet Respir Med 2015;3(07):563-577

136 Corcoran JP, Rahman NM. Effusions from infections: parapneumonic pleural effusion and empyema. In: Light RW, Lee YCG, eds. Textbook of Pleural Diseases. 3rd ed. Boca Raton, FL: CRC Press; 2016:295-330

137 Reichert M, Hecker M, Witte B, et al. Stage-directed therapy of pleural empyema. Langenbecks Arch Surg 2017;402(01): $15-26$

138 Ferrufino E, Mejía C, Ortiz de la Tabla V, Chiner E. Empyema caused by Legionella pneumophila. Arch Bronconeumol 2012;48 (03):102-103

139 Winn WC Jr, Myerowitz RL. The pathology of the Legionella pneumonias. A review of 74 cases and the literature. Hum Pathol 1981;12(05):401-422

140 Sahn SA, Light RW. The sun should never set on a parapneumonic effusion. Chest 1989;95(05):945-947

141 Akhan O, Ozkan O, Akinci D, Hassan A, Ozmen M. Image-guided catheter drainage of infected pleural effusions. Diagn Interv Radiol 2007;13(04):204-209

142 Kearney SE, Davies CW, Davies RJO, Gleeson FV. Computed tomography and ultrasound in parapneumonic effusions and empyema. Clin Radiol 2000;55(07):542-547

143 Schweigert M, Solymosi N, Dubecz A, et al. Surgical management of pleural empyema in the very elderly. Ann R Coll Surg Engl 2012;94(05):331-335 
374 Medical and Surgical Management of Empyema Godfrey et al.

144 Neff CC, vanSonnenberg E, Lawson DW, Patton AS. CT follow-up of empyemas: pleural peels resolve after percutaneous catheter drainage. Radiology 1990;176(01):195-197

145 Kho P, Karunanantham J, Leung M, Lim E. Debridement alone without decortication can achieve lung re-expansion in patients with empyema: an observational study. Interact Cardiovasc Thorac Surg 2011;12(05):724-727

146 Striffeler H, Gugger M, Im Hof V, Cerny A, Furrer M, Ris HB. Videoassisted thoracoscopic surgery for fibrinopurulent pleural empyema in 67 patients. Ann Thorac Surg 1998;65(02):319-323

147 Angelillo-Mackinlay T, Lyons GA, Piedras MB, Angelillo-Mackinlay D. Surgical treatment of postpneumonic empyema. World J Surg 1999;23(11):1110-1113

148 Cassina PC, Hauser M, Hillejan L, Greschuchna D, Stamatis G. Video-assisted thoracoscopy in the treatment of pleural empy- ema: stage-based management and outcome. J Thorac Cardiovasc Surg 1999;117(02):234-238

149 Roberts JR. Minimally invasive surgery in the treatment of empyema: intraoperative decision making. Ann Thorac Surg 2003;76(01):225-230, discussion 229-230

150 Solaini L, Prusciano F, Bagioni P. Video-assisted thoracic surgery in the treatment of pleural empyema. Surg Endosc 2007;21(02): 280-284

151 Cardillo G, Carleo F, Carbone L, et al. Chronic postpneumonic pleural empyema: comparative merits of thoracoscopic versus open decortication. Eur J Cardiothorac Surg 2009;36(05):914-918

152 Reichert M, Pösentrup B, Hecker A, et al. Thoracotomy versus video-assisted thoracoscopic surgery (VATS) in stage III empyema-an analysis of 217 consecutive patients. Surg Endosc 2018; 32(06):2664-2675 